\title{
Epstein-Barr virus latent membrane protein 1 (LMP1) regulates the aldehyde dehydrogenase (ALDH) positive cell population in nasopharyngeal carcinoma cell lines
}

\author{
J. WU ${ }^{1 \dagger}$, H. SU ${ }^{2 \dagger}$, G. LI ${ }^{1}$, Y. HUANG ${ }^{*}$
}

\begin{abstract}
${ }^{1}$ Affiliated Cancer Hospital \& Institute of Guangzhou Medical University, Guangzhou 510095, P. R. China; ${ }^{2}$ Department of medical examination, Sun Yat-sen University Cancer Center, Guangzhou 510060, P. R. China
\end{abstract}

Received July 17, 2018; revised December 18, 2019; accepted July 16, 2019

\begin{abstract}
Summary. - Nasopharyngeal carcinoma (NPC) is one of the severe head and neck carcinomas, which are rare in western countries but with high incidence in Southern Asia especially South China. NPC is relatively sensitive to radiotherapy, but the prognosis of patients in late stage is poor. The development of NPC is closely related to genetic background, Epstein-Barr virus (EBV) infection and life style. EBV latent membrane protein 1 (LMP1) is an oncoprotein, which plays important roles in the tumorigenesis of NPC. LMP1 was reported to be involved in the regulation of cancer stem cells (CSCs) by immunohistochemistry (IHC) and other surface marker staining methods, but not shown by aldehyde dehydrogenase 1 (ALDH-1) functional assay yet. In this study, we overexpressed LMP1 in two NPC cell lines and found elevated level of cytokeratin 19 (CK19) expression. CK19 is an undifferentiated keratin and a stem cell marker. We also have found an increased number of ALDH positive cells along with LMP1 overexpression in both cell lines. Our data demonstrate that LMP1 regulates the maintenance of ALDH-1 positive NPC cancer stem cells, thus shedding light on target therapy of NPC in clinical application.
\end{abstract}

Keywords: nasopharyngeal carcinoma; latent membrane protein 1; aldehyde dehydrogenase; cancer stem cells

\section{Introduction}

Nasopharyngeal carcinoma (NPC) is one of the most common head and neck cancers in Southern Asia and Northern Africa, with the incidence reaching 25 per 100,000 people, while in Europe and America, it is only 0.5-2 per 100,000 people (Thompson, 2006). The major etiologic factors for NPC are genetic susceptibility, endemic environment factors, and EBV infection.

The Epstein-Barr virus (EBV) belongs to human gammaherpes virus family. EBV is known as an infectious agent associated with several lymphoproliferative disorders, including Burkitt's lymphoma, Hodgkin's disease and non-

*Corresponding author. E-mail: huangyufan2018@163.com; phone: +86-20-66673664. ${ }^{\dagger}$ These authors contributed equally to this work. Abbreviations: $\mathrm{ALDH}=$ aldehyde dehydrogenase; $\mathrm{CSCs}=$ cancer stem cells; CK19 = cytokeratin 19; EBV = Epstein-Barr virus; $\mathrm{NPC}=$ nasopharyngeal carcinoma; $\mathrm{LMP} 1=$ latent membrane protein 1 lymphoproliferative malignancies, such as NPC, natural killer/T-cell (NKT) lymphoma, and gastric cancer (Lun et al., 2014). EBV latent membrane protein 1 (LMP1) is a 66 $\mathrm{kDa}$ transmembrane protein containing transmembranespanning loops (Dawson et al., 2012). LMP1 has two NF- $\mathrm{BB}$ activating domains in its intracellular carboxy terminus (carboxy-terminal acribatin region 1/2, CTAR1/2). CTAR1 is required for B-lymphocyte transformation (Edwards et al., 2015).

Cancer stem cells (CSCs) have been considered as the origin of tumorigenesis, therapeutic resistance, recurrence and distant metastasis (Reya et al., 2001; Visvader and Lindeman, 2008; Wang et al., 2007). The CSCs like side population of cells in NPC were first defied by Zeng's group with Hoechst 33342 staining (Wang et al., 2007). Kondo et al. reported that LMP1 induced the CD44 high CD24 low CSCs in NPC cells (Kondo et al., 2011). Aldehyde dehydrogenase 1 (ALDH-1) is another functional marker for CSCs. Wu et al. (Wu et al., 2013; Yu et al., 2013) found that ALDH positive 
NPC cells expressed high level of stem cells related proteins like OCT4, Bmi-1, KLF4 and Sox2. These cells have high proliferation rate and differentiation ability, strong colony/ sphere formation and migration ability compared with their negative counterparts. Multivariate analysis indicated that ALDH could be an independent prognostic marker for NPC. Luo et al. (2013) detected the biomarker profile of CSCs and epithelial-mesenchymal transition (EMT) by performing immunohistochemical staining (IHC) on tissue array of NPC samples. However, the ALDH-1 staining for flow cytometry analysis has not been reported in NPC yet.

In this study, LMP1 was overexpressed in two NPC cell lines (CNE2 and Hone1), the ALDH positive cells were detected by flow cytometry and the molecular changes related with CSC and EMT were analyzed by Western blot assay. We found that overexpressed LMP1 led to enhancement of ALDH positive CSC population in both NPC cell lines.

\section{Material and Methods}

Human cell lines. Human NPC cell lines CNE2 and Hone1 were maintained in our lab. Both cell lines were maintained in RPMI1640 (Gibco Life Technologies, USA) with 10\% fetal bovine serum (FBS, Gibco Life Technologies). All cells were cultured in humidified incubator at $37^{\circ} \mathrm{C}$ in $5 \% \mathrm{CO}_{2}$. Investigation has been conducted in accordance with the ethical standards and international guidelines.

Plasmid transfection. The control p-LXSN plasmid and LMP1 containing plasmid pLMP1 (Ke Lei Biological Technology, China) were transfected to CNE2 and Hone1 cells separately by Lipofectamine 2000 (Invitrogen, USA) following the manufacturer's instructions. Then the cell lysates were collected at 48 and $72 \mathrm{~h}$ after transfection and subjected to Western blot analysis.

Western blot assay. Cells were harvested and lysed by RIPA lysis buffer ( $1 \%$ NP-40, $1 \%$ sodium deoxycholate, $0.1 \%$ SDS, $150 \mathrm{mM} \mathrm{NaCl}$ and $10 \mathrm{mM} \mathrm{Na}_{2} \mathrm{HPO}_{4}, \mathrm{pH} 7.2$; Beyotime Institute of Biotechnology, Japan), supplemented with protease inhibitor cocktail (Roche Diagnostics GmbH, Germany). Immunoblotting was performed with standard protocols as previously described (Wang et al., 2014). The following antibodies were used: mouse antiLMP1 (1:1000, Santa Cruz Biotechnology, USA), mouse anti-CK19 (1:1000, Cell Signaling Technology, USA), mouse anti-GAPDH (1:10,000, Protein Tec Group, USA). The membranes were incubated with primary antibodies at $4^{\circ} \mathrm{C}$ overnight and washed three times with phosphate buffered saline containing Tween (PBST). Horseradish peroxidase conjugated goat anti-mouse (Beyotime Institute of Biotechnology) and goat anti-rabbit (Life Technologies, USA) secondary antibodies were applied for $30 \mathrm{~min}$ at room temperature. The membranes were then washed three times with PBST and incubated with enhanced chemiluminescence-reagent (Millipore, USA) according to the manufacturer's instructions. Next, the membranes were exposed to ECL sensitive films (Hyperfilm ECL; GE Healthcare Bio-Sciences, USA), and developed using an OPTIMAX X-Ray film processor (Protec GmbH \& Co. $\mathrm{KG}$, Germany). We used GAPDH as an internal loading control.

ALDH positive cell detection. The ALDH positive cells were identified using the ALDEFLUOR ${ }^{\circ}$ assay kit (Stem Cell Technologies, Canada) following the manufacturer's instructions. The tested cells were suspended in PBS with ALDH substrate precursor BodipyTMaminoacetaldehyde diethyl acetal (BAAA-DA), which is converted into Bodipy-aminoacetaldehyde (BAAA) when exposed to acidic environment. The negative control (NC) cells were suspended in PBS with both BAAA-DA and ALDH inhibitor diethylaminobenzaldehyde (DEAB). The cells were then incubated at $37^{\circ} \mathrm{C}$ for $40 \mathrm{~min}$ and re-suspended in ALDEFLUOR assay buffer on ice. Propidium iodide was added prior to flow cytometry analysis to exclude dead cells. Then the positive cells were detected by a standard flow cytometry in the green fluorescence channel (520-540 nm). The detailed staining protocol refers to the website of Stem Cell Technologies.

Statistical analysis. The data for in vitro study were expressed as mean \pm standard error. Student's $t$ test was used to determine any statistically significant differences. All p-values quoted were two sided and $\mathrm{p}<0.05$ was considered statistically significant. Statistical analysis was performed with SPSS 16.0 (SPSS, Inc, USA).

\section{Results}

Expression of LMP1 increased the level of CK19 in NPC cell lines

In order to define the role of LMP1 in CSC regulation, we transiently transfected LMP1 to cell lines, CNE2 and Hone1, both of which were poorly differentiated NPC cells. To confirm the transfection efficiency, we collected cell lysates at $48 \mathrm{~h}$ (passage 1) and $72 \mathrm{~h}$ (passage 2) after transfection, and then performed Western blot assay. LMP1 was successfully expressed in both CNE2 and Hone1 cell lines, while the expression level was higher in passage 1 than that in passage 2 in both cell lines (Fig. 1). CK19 was detected as an undifferentiated keratin and a normal stem cell marker (Kondo et al., 2011). Upon overexpression of LMP1, level of CK19 in CNE2 and Hone1 cells was elevated in both passage 1 and 2 (Fig. 1). Our data suggest that LMP1 affects the switch of NPC cells into their undifferentiated state.

Expression of LMP1 increased ALDH positive CSC population in NPC cell lines

To investigate whether LMP1 is involved in CSC regulation of NPC, we detected the ALDH positive cells in CNE2 and Honel cell lines by flowcytometry. We found that the number of ALDH positive cells increased in p-LMP1 CNE2 cells in comparison to p-LXSN in passage 1 ( $48 \mathrm{~h}$ after transfection), $(27.46 \% \pm 1.67$ versus $18.23 \% \pm 2.27, \mathrm{p}<0.005)$ 
(a)

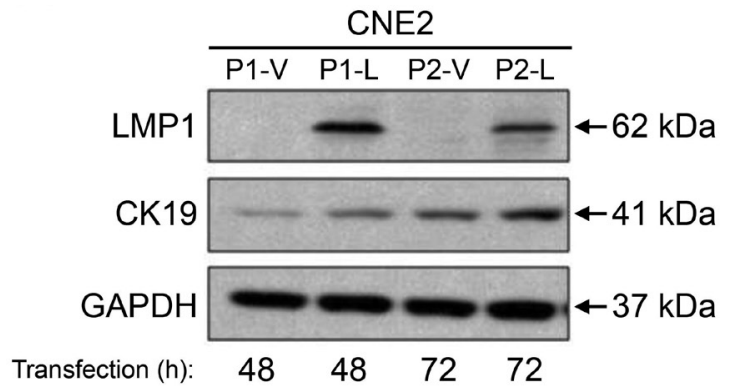

(b)

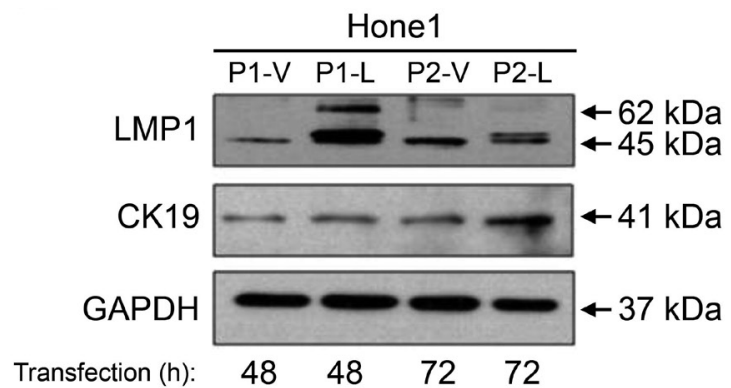

Fig. 1

LMP1 was successfully expressed in NPC cell lines

(a) In CNE2 cells, LMP1 expression was lower at $72 \mathrm{~h}(\mathrm{P} 2-\mathrm{L})$ than at $48 \mathrm{~h}$ after transfection (P1-L), while there was no LMP1 expression in vector control (p-LXSN) cells after $48 \mathrm{~h}(\mathrm{P} 1-\mathrm{V})$ or $72 \mathrm{~h}(\mathrm{P} 2-\mathrm{V})$ after transfection. CK19 was increased upon the enhancement of LMP1 in both passage 1 (P1-L) and 2 (P2-L). (b) In Hone1 cells, LMP1 had higher expression at $48 \mathrm{~h}$ (P1-L) after transfection than at $72 \mathrm{~h}$ (P2-L) and also compared with vector control (pLXSN) after $48 \mathrm{~h}(\mathrm{P} 1-\mathrm{V})$ and $72 \mathrm{~h}(\mathrm{P} 2-\mathrm{V})$ after transfection. CK19 was elevated with the increase of LMP1 in both passages 1 and 2. GAPDH was used as loading control. $(\mathrm{P}=$ passage, $\mathrm{V}=$ vector control, $\mathrm{L}=\mathrm{LMP1}$ overexpression. $)$.

(a)
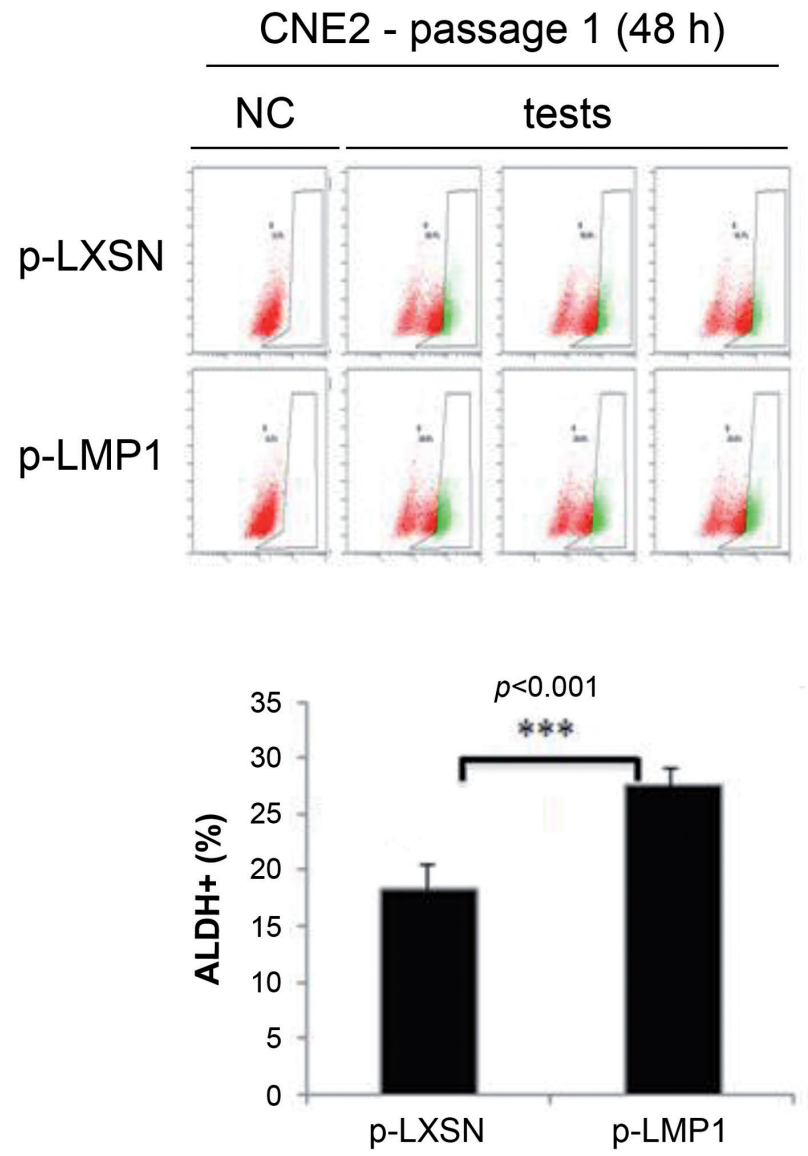

(b)

\section{CNE2 - passage $2(72 \mathrm{~h})$}
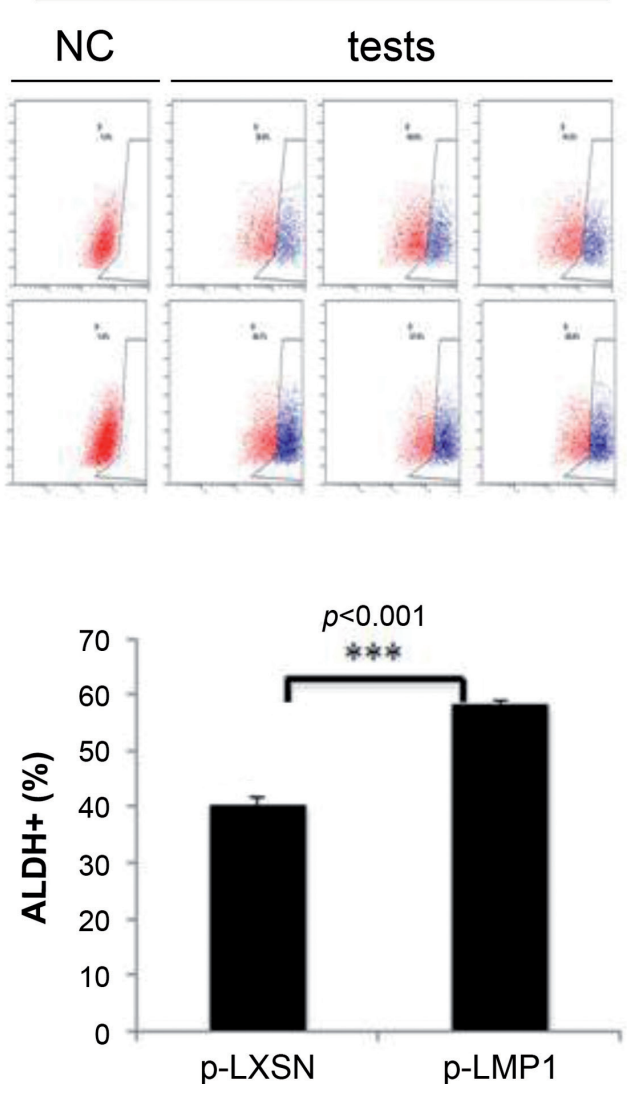

Fig. 2

ALDH positive cell population was enhanced upon LMP1 overexpression in CNE2 cell line

(a) In CNE2 cells, ALDH positive cells were detected at $48 \mathrm{~h}$ after transfection (passage 1). (b) The ALDH positive cells were detected at $72 \mathrm{~h}$ after transfection (passage 2). Upper panel indicates the flow-cytometry profiles and lower panel shows the statistical analysis results. There was a higher number of ALDH positive cells in LMP1 transfected cells in both passages. NC = negative control, with DEAB; Tests = without DEAB. 
(Fig. 2a). While in passage 2 (72 $\mathrm{h}$ after transfection), the number of ALDH positive cells was $58.37 \% \pm 0.67$ in LMP1 overexpressed cells and $40.40 \% \pm 1.35$ in vector control cells ( $\mathrm{p}<0.0001$ ) (Fig. 2b). Comparing passage 1 and passage 2, the ratio of ALDH positive cell levels in p-LMP1 cells versus p-LXSN cells reduced from 1.51 to 1.44 which was in accordance with the drop of LMP1 level.

The number of ALDH positive cells in Hone1 passage 1 cells was $58.30 \% \pm 3.42$ in p-LMP1 and $34.43 \% \pm 7.43$ in p-LXSN (48 h after transfection, p <0.01) (Fig. 3a). However, there was only $43.57 \% \pm 0.81$ of ALDH positive cells in p-LMP1 while $45.56 \% \pm 1.26$ in p-LXSN of passage $2(72 \mathrm{~h}$ after transfection, $\mathrm{p}>0.05$ ) (Fig. 3b). The ratio of ALDH positive cells in p-LMP1 versus p-LXSN decreased dramatically in passage 2 compared with passage 1 (from 1.69 to 0.96 ), which was possibly due to the reduction of LMP1 expression level after passage. Therefore, our data demonstrate that in NPC the LMP1 is involved in the regulation of ALDH positive CSC cells.

\section{Discussion}

Cell surface marker staining is a reliable method for CSC isolation. CD44 is a cell surface proteoglycan and glycoprotein related to body immune reaction (Janisiewicz et al.; 2012; Su et al., 2011). Stem cell markers OCT4 and Bmi-1 were highly expressed in CD44 positive NPC cells which are resistant to radiotherapy and cisplatin/docetaxel treatment (Lun et al., 2012). CD133, another cell surface glycoprotein, is originally reported as a specific marker of normal stem cells. CD133 positive NPC cells exhibited strong (a)
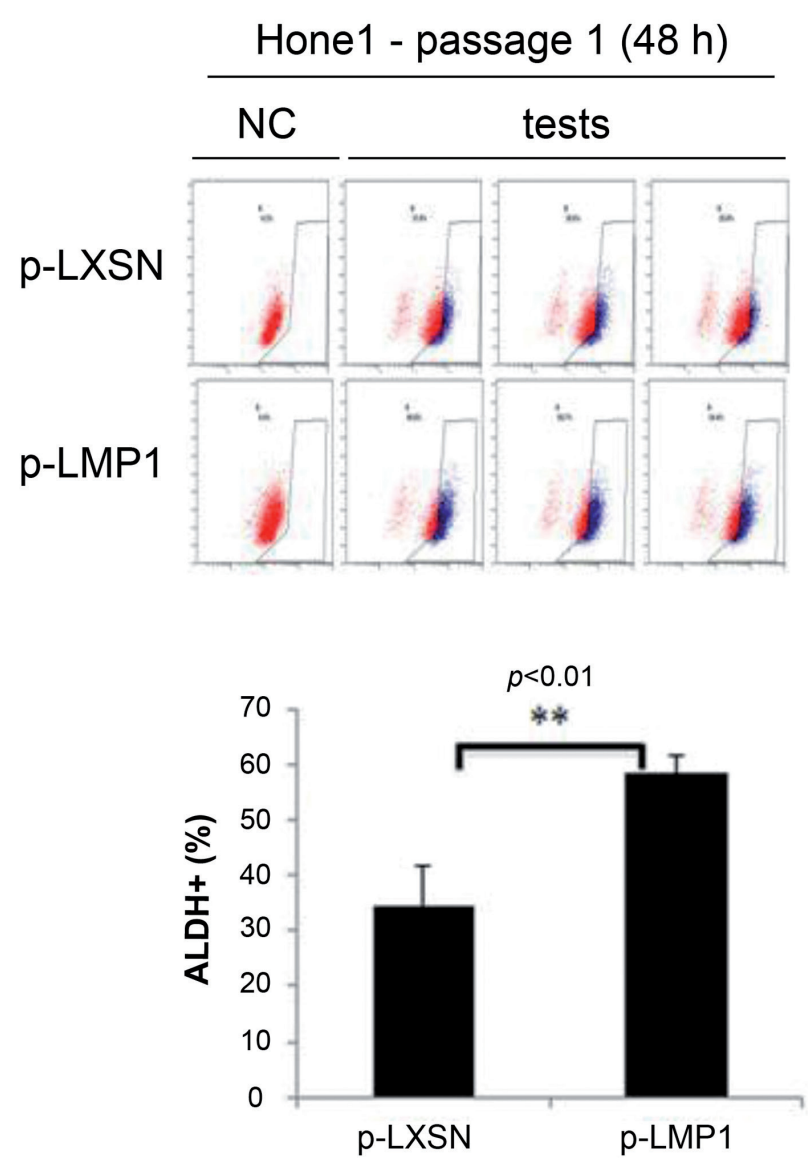

(b)
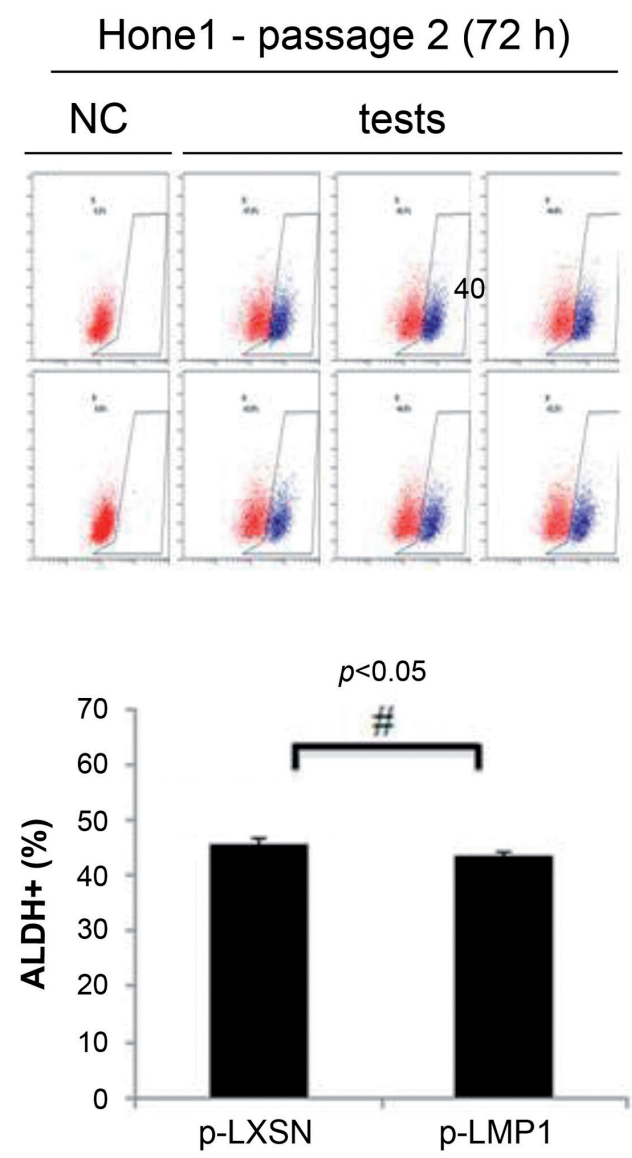

Fig. 3

ALDH positive cell population was enhanced upon LMP1 overexpression in Hone1 cell line

(a) In Honel cells, ALDH positive cells were detected at $48 \mathrm{~h}$ after transfection (passage 1). (b) The ALDH positive cells were detected at $72 \mathrm{~h}$ after transfection (passage 2). Upper panel indicates the flow-cytometry profiles and lower panel shows the statistical analysis results. There was a higher number of ALDH positive cells in LMP1 transfected cells after $48 \mathrm{~h}$, however there was comparable number of ALDH positive cells after $72 \mathrm{~h}$ in both transfected and non-transfected cells. $\mathrm{NC}=$ negative control, with DEAB; Tests = without DEAB. 
self-renewal, proliferation and differentiation ability, as well as the remarkable tumor formation ability in vivo (Zhuang et al., 2013). Several studies have reported that EBV LMP1 is involved in the modulation of CSC of NPC with different detection methods, such as flow cytometry and IHC. However, investigating the CSC population with ALDEFLUOR ${ }^{\circledast}$ kit has not been reported in NPC.

Cytokeratin 19 (CK19) found in many epithelial malignant tumors, is a member of 20 -member cytokeratin family that encompasses the intermediate filaments of epithelial cells. In lung cancer, CK19 expressed in non-stratified or pseudostratified epithelium lining of the bronchial tree, and was reported to be overexpressed in cancer specimens (Xu et al., 2015). Serum cytokeratin fraction 21-1 (CYFRA 21-1), a soluble cytoplasmic fragment of CK19, is released to the circulatory system after tumor cell death, and its level may reflect the extent of tumor necrosis (Wei et al., 2014). CK19 was found in $53.3 \%$ pancreatic neuroendocrine tumors and correlated with larger tumor, increased distant metastasis, and lymphovascular and/or perineural spread (Son et al., 2015).

EBV LMP1 is an important oncogenic protein during the tumorigenesis of NPC. Wu et al. (2015) described the immunogenicity of LMP1 and its induction of anti-vascular immune response in a transplantable tumor model in immunocompetent BALB/c mice. They found that the CD4 T cells play an important role in the LMP1 specific immunity in vivo. Furthermore, LMP1 induced upregulation of interleukin-32 (IL-32, a recently discovered pro-inflammatory cytokine) at both mRNA and protein levels through NF- $\kappa \mathrm{B}$ pathway (Lai et al., 2015).

Chimeric antigen receptor $\mathrm{T}$-cell therapy (CAR-T) therapy is one of the hottest areas in cancer therapy right now (Flemming, 2014). Chen et al. (2012) identified a human Fab fragment HELA-Fab that specifically recognized a polypeptide in the extra-membrane domain of LMP1. Based on this, Tang et al. (2014) constructed another chimeric antigen receptor (Carter et al., 2002), HELA/CAR, which consists of the anti-LMP1 scFv, IgG1 CH2CH3, and a CD28/ CD3 expression cassette. In this way, a novel approach using CAR-T targeting the LMP1 protein may improve EBV-target $\mathrm{T}$ cell therapy in the future.

Acknowledgments. This work was supported by Guangzhou key medical discipline construction project fund.

\section{References}

Carter KL, Cahir-McFarland E, Kieff E (2002): Epstein-barr virus-induced changes in B-lymphocyte gene expression. J. Virol. 76, 10427-10436. https://doi.org/10.1128/ JVI.76.20.10427-10436.2002
Chen R, Zhang D, Mao Y, Zhu J, Ming H, Wen J, Ma J, Cao Q, Lin H, Tang Q et al. (2012): A human Fab-based immunoconjugate specific for the LMP1 extracellular domain inhibits nasopharyngeal carcinoma growth in vitro and in vivo. Mol. Cancer Ther. 11, 594-603. https://doi. org/10.1158/1535-7163.MCT-11-0725

Dawson CW, Port RJ, Young LS (2012): The role of the EBV-encoded latent membrane proteins LMP1 and LMP2 in the pathogenesis of nasopharyngeal carcinoma (NPC). Semin. Cancer Biol. 22, 144-153. https://doi.org/10.1016/j. semcancer.2012.01.004

Edwards RH, Marquitz AR, Raab-Traub N (2015): Changes in expression induced by Epstein-Barr virus LMP1-CTAR1: potential role of bcl3. MBio 6, pii e00441-15. https://doi. org $/ 10.1128 / \mathrm{mBio} .00441-15$

Flemming A (2014): Deal watch: Pfizer and GSK join race for T cell cancer therapies. Nat. Rev. Drug. Discov. 13, 568-569. https://doi.org/10.1038/nrd4402

Janisiewicz AM, Shin JH, Murillo-Sauca O, Kwok S, Le QT, Kong C, Kaplan MJ, Sunwoo JB (2012): CD44(+) cells have cancer stem cell-like properties in nasopharyngeal carcinoma. Int. Forum Allergy Rhinol. 2, 465-470. https:// doi.org/10.1002/alr.21068

Kondo S, Wakisaka N, Muramatsu M, Zen Y, Endo K, Murono S, Sugimoto H, Yamaoka S, Pagano JS, Yoshizaki T (2011): Epstein-Barr virus latent membrane protein 1 induces cancer stem/progenitor-like cells in nasopharyngeal epithelial cell lines. J. Virol. 85, 11255-11264. https://doi. org/10.1128/JVI.00188-11

Lai KY, Chou YC, Lin JH, Liu Y, Lin KM, Doong SL, Chen MR, Yeh TH, Lin SJ, Tsai C.H (2015): Maintenance of Epstein-Barr virus latent status by a novel mechanism, latent membrane protein 1-induced interleukin-32, via the protein kinase C delta pathway. J. Virol. 89, 5968-5980. https://doi. org/10.1128/JVI.00168-15

Lun SW, Cheung ST, Cheung PF, To KF, Woo JK, Choy KW, Chow C, Cheung CC, Chung GT, Cheng AS et al. (2012): CD44+ cancer stem-like cells in EBV-associated nasopharyngeal carcinoma. PLoS One 7, e52426. https://doi.org/10.1371/ journal.pone. 0052426

Lun SW, Cheung ST, Lo KW (2014): Cancer stem-like cells in Epstein-Barr virus-associated nasopharyngeal carcinoma. Chin. J. Cancer 33, 529-538. https://doi.org/10.5732/ cjc. 014.10081

Luo W, Yao K (2013): Molecular characterization and clinical implications of spindle cells in nasopharyngeal carcinoma: a novel molecule-morphology model of tumor progression proposed. PLoS One 8, e83135. https://doi.org/10.1371/ journal.pone.0083135

Reya T, Morrison SJ, Clarke MF, Weissman IL (2001): Stem cells, cancer, and cancer stem cells. Nature 414, 105-111. https://doi.org/10.1038/35102167

Son EM, Kim JY, An S, Song KB, Kim, SC, Yu E, Hong SM (2015): Clinical and prognostic significances of Cytokeratin 19 and KIT expression in surgically resectable pancreatic neuroendocrine tumors. J. Pathol. Transl. Med. 49, 30-36. https://doi.org/10.4132/jptm.2014.10.23 
Su J, Xu XH, Huang Q, Lu MQ, Li DJ, Xue F, Yi F, Ren JH, Wu YP (2011): Identification of cancer stem-like CD44+ cells in human nasopharyngeal carcinoma cell line. Arch. Med. Res. 42, 15-21. https://doi.org/10.1016/j. arcmed.2011.01.007

Tang X, Zhou Y, Li W, Tang Q, Chen R, Zhu J, Feng Z (2014): T cells expressing a LMP1-specific chimeric antigen receptor mediate antitumor effects against LMP1-positive nasopharyngeal carcinoma cells in vitro and in vivo. J. Biomed. Res. 28, 468-475.

Thompson L (2006): World Health Organization classification of tumours: pathology and genetics of head and neck tumours. Ear, nose, throat J. 85, 74. https://doi. org/10.1177/014556130608500201

Visvader JE, Lindeman GJ (2008): Cancer stem cells in solid tumours: accumulating evidence and unresolved questions. Nat Rev Cancer 8, 755-768. https://doi.org/10.1038/ $\underline{\operatorname{nrc} 2499}$

Wang J, Guo LP, Chen LZ, Zeng YX, Lu SH (2007): Identification of cancer stem cell-like side population cells in human nasopharyngeal carcinoma cell line. Cancer Res. 67, 3716-3724. https://doi.org/10.1158/0008-5472.CAN$\underline{06-4343}$

Wang J, Huang Y, Guan Z, Zhang JL, Su HK, Zhang W, Yue CF, Yan M, Guan S, Liu QQ (2014): E3-ligase Skp2 predicts poor prognosis and maintains cancer stem cell pool in nasopharyngeal carcinoma. Oncotarget 5, 5591-5601. https://doi.org/10.18632/oncotarget.2149
Wei Z, Zeng X, Xu J, Duan X, Yang J, Xie Y (2014): Prognostic value of the pretreatment serum level of cytokeratin fraction 21-1 in undifferentiated nasopharyngeal carcinoma: a study of 332 cases. Head Neck 36, 71-76. https://doi. org/10.1002/hed.23261

Wu A, Luo W, Zhang Q, Yang Z, Zhang G, Li S, Yao K (2013): Aldehyde dehydrogenase 1 , a functional marker for identifying cancer stem cells in human nasopharyngeal carcinoma. Cancer Lett. 330, 181-189. https://doi.org/10.1016/j. canlet.2012.11.046

Wu TS, Wang LC, Liu SC, Hsu TY, Lin CY, Feng GJ, Chen JM, Liu HP, Chung IC, Yen TC et al. (2015): EBV oncogene NLMP1 induces CD4 T cell-mediated angiogenic blockade in the murine tumor model. J. Immunol. 194, 4577-4587. https://doi.org/10.4049/jimmunol.1400794

Xu Y, Xu L, Qiu M, Wang J, Zhou Q, Yin R (2015): Prognostic value of serum cytokeratin 19 fragments (Cyfra 21-1) in patients with non-small cell lung cancer. Sci. Rep. 5, 9444. https:// doi.org/10.1038/srep09444

Yu F, Sim AC, Li C, Li Y, Zhao X, Wang DY, Loh KS (2013): Identification of a subpopulation of nasopharyngeal carcinoma cells with cancer stem-like cell properties by high aldehyde dehydrogenase activity. Laryngoscope 123, 1903-1911. https://doi.org/10.1002/lary.24003

Zhuang HW, Mo TT, Hou WJ, Xiong GX, Zhu XL, Fu QL, Wen WP (2013): Biological characteristics of CD133(+) cells in nasopharyngeal carcinoma. Oncol. Rep. 30, 57-63. https://doi.org/10.3892/or.2013.2408 